\title{
Phrenic Nerve Injury
}

National Cancer Institute

\section{Source}

National Cancer Institute. Phrenic Nerve Injury. NCI Thesaurus. Code C99016.

Damage to the phrenic nerve. 